\title{
DISTRIBUCIÓN ESPACIAL Y ANÁLISIS AMBIENTAL DE LA FLORA VASCULAR DE LOS PIRINEOS
}

\author{
Spatial distribution and environmental analysis \\ of vascular flora of the Pyrenees \\ D. Gómez ${ }^{1 *}$, M.B. García ${ }^{1}$, X. Font Castell ${ }^{2}$ y I. Aizpuru Oiarbide ${ }^{3}$ \\ 'Instituto Pirenaico de Ecología (CSIC), 22700-Jaca (Huesca). \\ ${ }^{2}$ Centre de Documentació de Biodiversitat Vegetal (CeDocBiV), Baldiri Reixac, 2. 08028-Barcelona. \\ ${ }^{3}$ Sociedad de Ciencias Aranzadi, Alto de Zorroaga Bidea, 11, 20014-Donostia, Gipuzkoa. \\ Identificador ORCID de los autores y e-mail: \\ D. Gómez: http://orcid.org/0000-0002-9738-8720 E-mail:dgomez@ipe.csic.es \\ M.B.García: http://orcid.org/0000-0003-4231-6006 E-mail: mariab@ipe.csic.es \\ X. Font Castell: http://orcid.org/0000-0002-7253-8905 E-mail: xfont@ub.edu \\ I. Aizpuru Oiarbide: http://orcid.org/0000-0003-0386-9601 E-mail: iñaki.aizpuru@ihobe.net \\ * Autor corresponsal
}

\begin{abstract}
Recibido: 19-04-2017. Aceptado: 12-07-2017. Fecha de publicación on-line: 06/10/2017
Citation / Cómo citar este artículo: Gómez, D., García, M.B., Font Castell, X., Aizpuru Oiarbide, I. (2017). Distribución espacial y análisis ambiental de la flora vascular de los Pirineos. Pirineos, 172, e028. doi: http://dx.doi.org/10.3989/ pirineos.2017.172003
\end{abstract}

RESUMEN: La reciente publicación web del Atlas de la flora vascular de los Pirineos permite ahora delimitar la diversidad florística de la cordillera y analizar su distribución territorial y algunas afinidades ambientales con el fin de contribuir a su caracterización ecológica y a su conservación. La flora vascular de los Pirineos reúne 3.652 plantas vasculares autóctonas, incluyendo especies y subespecies, lo que sitúa a la cordillera como el segundo núcleo de diversidad florística en Europa, tras los Alpes. Entre los seis sectores geográficos considerados, los que albergan mayor riqueza de plantas son el Central-Sur (76\% del total) y los dos orientales (ambos con el 75\%). En el gradiente altitudinal, el piso montano es el que alberga mayor número de taxones ( $87 \%$ del total). Respecto a la corología, el 32\% de la flora pirenaica son plantas eurosiberianas, el 29\% mediterráneas, las orófitas alpinas y boreoalpinas son el $12,6 \%$ y los endemismos un 5\%. Por sus formas biológicas, predominan los hemicriptófitos (40\%) y los terófitos $(20,4 \%)$. Conforme se asciende en altitud, aumentan los caméfitos y disminuyen los terófitos. Por su preferencia edáfica, un $35 \%$ de la flora es calcícola y un $21 \%$ silicícola. En cuanto a la representación por hábitats, cerca del $30 \%$ de las plantas viven en pastos, el 16\% en humedales, los ambientes rocosos, bosques, matorrales y comunidades ruderales albergan un número similar de plantas (entre el 12 y 13\% cada uno). Por último, teniendo en cuenta la naturalidad de los hábitats, el $47 \%$ de las plantas vive en los de alta o muy alta naturalidad, aunque cerca de una cuarta parte se encuentra en los más humanizados.

PALABRAS CLAVE: Biodiversidad florística; distribución espacial; distribución altitudinal; corología; formas biológicas; abundancia; naturalidad de los hábitats. 


\begin{abstract}
The recent "on line" edition of the Atlas of vascular flora of the Pyrenees, allow us now to delimit the floristic diversity and to analyze the spatial distribution and some environmental features to contribute to their ecological study and conservation. The native vascular flora of the Pyrenees consists in 3,652 species and subspecies of vascular plants. This figure places the Pyrenees as the second most important point of Europe plant diversity, after the Alps. Considering 6 geographical sectors, the central-south (76\%) and both the easterns $(75 \%)$ shelter the highest plant abundance. In the altitudinal gradient, the montane belt holds the highest plant richness ( $87 \%$ of the total). With respect to chorology, $32 \%$ of plants are eurosiberians and $29 \%$ mediterraneans, whereas alpine orophytes and boreoalpines account for $12.6 \%$ and $5 \%$ are endemisms. Concerning life-forms, hemicryptophytes (44\%) and therophytes $(20.4 \%)$ predominate, although the later decrease with altitude, while chamaephytes increase. Looking at the edafic affinity, $35 \%$ of plants are calcicolus and $21 \%$ silicicolus. Distribution according to habitats shows that near $30 \%$ of the flora occur in grasslands, $16 \%$ in wetlands, and a similar percentage (around 12-13\%) in rocks, forest, shrublands and anthropic plant communities. Finally, taking into account the habitat naturalness, $47 \%$ of plants occur in high or very high preserved habitats, although almost a quarter of plants live in the most disturbed ones.
\end{abstract}

KEY WORDS: Plant biodiversity; spatial distribution; altitudinal distribution; chorology; life-forms; abundance; habitat naturalness.

\section{Introducción}

El interés por la localización de las plantas se constata en los tratados de botánica de la antigüedad desde Dioscórides en el siglo I d.C., pero hasta finales del XVIII no puede hablarse de una "geografía botánica", que cobra cuerpo como una rama científica de la botánica hace apenas dos siglos (Humboldt, 1805) y con la denominación de Geobotánica (Rübel, 1917) abarca el estudio de las plantas a escala de taxón, de sus comunidades y del paisaje vegetal que conforman (Bolòs, 1963).

La exploración botánica de los Pirineos cuenta con una larga historia de más de tres siglos (Vigo, 1976), cuyos inicios cabe situar en los viajes y estudios de P. Tournefort en 1680, Goüan (1765), Quer (1762) y Asso (1779 y 1781) y, ya en el siglo XIX, los de De Candolle en 1858 y 1868 y Ramond (1801). En este mismo siglo vieron la luz los trabajos de Lapeyrouse (1813-1818), el catálogo del Pirineo oriental (Bentham, 1826) y los del conjunto de los Pirineos de Zetterstedt (1857) y Bubani (1897-1902). La Flora Pyrenaea de este último autor todavía constituye una referencia capital en las prospecciones de la Cordillera, y sigue guardando muchas citas florísticas de gran interés todavía por verificar. A finales del siglo XIX y comienzos del XX se editaron las Floras de Francia (Coste, 1901-1906) y España (Willkomm \& Lange, 1861-1880 y Willkomm, 1893) y la botánica pirenaica cobró un decidido impulso en ambas vertientes gracias a un amplio elenco de botánicos de distinta formación y procedencia (Saule-Sorbé \& Largier, 2010). Resulta imposible reseñar aquí los numerosos estudios florísticos del pasado siglo que han dado lugar a centenares de publicaciones, entre las que destacamos los catálogos de Andorra (Losa \& Montserrat, 1951), de Francia (Saule, 1991), dels "Paisös Catalans" (Bolòs \& Vigo, 1984-2001), del Pirineo occidental español (Villar, 1980), de los Pirineos de Aragón (Villar et al., 19972001), del País Vasco (Aseginolaza et al., 1985) y de Navarra (Lorda, 2001 y 2013). Una reseña más detallada de las publicaciones botánicas sobre los Pirineos puede consultarse en Villar \& Sesé, (1991) y Gómez et al., (2005).
A pesar de la prolija bibliografía mencionada, la flora de la cordillera en su conjunto no pudo ser revisada y completada en el último siglo, en gran parte debido al predominio de los territorios administrativos sobre los geográficos considerados en muchos estudios, aunque hay que destacar el esfuerzo continuado en este objetivo de Gaussen (1953-1981) y los análisis ya realizados a escala regional (Villar et al., 1997-2001). No obstante, el prolongado y tortuoso camino de la flora pirenaica es similar al que han seguido las floras de otras complejas cadenas montañosas que no se han completado hasta fechas recientes, como la de los Alpes (Aeschimann et al., 2004), o bien todavía están pendientes de recapitularse como la de los Cárpatos o los Balcanes. Disponer de floras de las grandes cadenas montañosas es indispensable para el avance de la ecología vegetal y la conservación de la biodiversidad, porque las grandes montañas albergan la mayor parte de la flora vascular en las zonas templadas del planeta, y en el continente europeo, las "cordilleras alpinas" tienen una gran parte de la flora y la mayor representación de especies raras y endemismos (Walter, 1954; Walter \& Straka 1970; Takhtajan, 1986).

En los años 2011-2014, en el marco de un proyecto de la Comunidad de Trabajo de los Pirineos (financiado por el Fondo Europeo de Desarrollo Regional (FEDER) de la Comisión Europea), se completó el catálogo de la flora vascular por un equipo de más de 30 botánicos de distintas instituciones y centros de investigación de todo el territorio. Los resultados de ese proyecto están editados en formato digital en el Atlas de la Flora Vascular de los Pirineos (http://www.florapyrenaea.org), todavía en fase de revisión. En dicha web se incluye una ficha con información taxonómica, ecológica y fenológica y un mapa de distribución de cada taxón, a partir de la recopilación de cerca de dos millones de citas florísticas, lo que permite ahora la elaboración de mapas de distribución con un grado de detalle muy destacado en el ámbito de las grandes cordilleras de Europa y la interpretación geobotánica de la distribución de la flora (Bolòs, 1963). Tomando como base el listado de taxones y los datos de las fichas reunidas en dicho Atlas, hemos revisado y completado con las mencionadas floras regionales distintos aspectos de la 
distribución de la flora pirenaica para analizar algunos patrones básicos de la diversidad y abundancia de la flora vascular. Confiamos en que esta información permitirá indagar en sus causas, comparar patrones entre distintos territorios de montaña, y servir de base a la gestión de la conservación vegetal.

\section{Material y métodos}

\subsection{Territorio de estudio}

Los Pirineos (Figura 1) se extienden en una superficie cercana a los $50.000 \mathrm{~km}^{2}$ a lo largo de $430 \mathrm{~km}$ entre el mar Cantábrico (Jaizkibel) y el Mediterráneo (Cabo de Creus), con una anchura máxima de $150 \mathrm{~km}$. Dos tercios de la superficie total se sitúan en la vertiente española. La máxima altitud se mide en el Pico de Aneto (3.404 m) y más de 150 cumbres sobrepasan los $3.000 \mathrm{~m}$ de altitud. Entre el Canigó (2.785 m), situado $50 \mathrm{~km}$ al oeste del Mediterráneo, y el Pico de Anie $(2.504 \mathrm{~m}), 100 \mathrm{~km}$ al este del Cantábrico, la cadena montañosa está jalonada de cumbres que sobrepasan los $2.000 \mathrm{~m}$ de altitud a lo largo de $300 \mathrm{~km}$.

En cuanto a la estructura geológica, de forma muy simplificada, la cordillera pirenaica, con disposición general Este-Oeste, es el resultado de la compresión de la placa ibérica entre la europea y la africana. Los materiales comprimidos cabalgan en general sobre la placa europea dándole una fisonomía en anchura más corta y accidentada en la vertiente Norte y más ancha y con menores ángulos sobre la horizontal en la Sur. El núcleo longitudinal lo forman materiales paleozoicos (primarios y triásicos) muy diversos, con origen en sedimentación marina, sedimentación continental, e intrusiones magmáticas que forman principalmente arcillas, areniscas, calizas, pizarras, esquistos y granitos. Este núcleo muy tectonizado está actualmente denudado, en forma irregular, de su cobertura mesozóica (secundaria y paleocena) que está compuesta principalmente por arcillas, areniscas y calizas de sedimentación marina. Los materiales mesozóicos, no obstante, todavía cubren gran parte del núcleo de la cordillera y sus calizas compactas vertebran las sierras interiores y exteriores formando en la vertiente Norte una notable fisonomía de cañones y en la Sur amplias depresiones internas a la cordillera. Estas depresiones durante el Paleógeno (Terciario) fueron generosamente rellenadas con materiales de erosión de la cordillera, generando grandes espesores de margas, areniscas, flysch y conglomerados que afectaron a la cuenca del Ebro todavía no diferenciada, mientras que en la vertiente Norte, por su fisonomía, estos sedimentos del Cenozoico fueron casi íntegramente depositados en las cuencas de Aquitania y del Garona. Durante el Neógeno (Terciario) con la emersión total de la cordillera, los movimientos erosivos dominaron sobre los sedimentarios, no produciéndose más acumulaciones de materiales geológicos reseñables que los fluviales. Pese a su ralentización, la orogenia todavía provocó importantes fracturas y deslizamientos de mantos (Gavar- nie, Cotiella), lo cual generó una mayor denudación del núcleo paleozoico, así como la formación de pliegues sobre las depresiones internas y las sierras exteriores, la deposición y denudación de los conglomerados masivos, y el despegue definitivo de las sierras exteriores. Durante el Cuaternario continuó la tendencia erosiva dominantemente fluvial y glaciar, con sus sedimentos como únicas acumulaciones geológicas destacables. (Solé i Sabarís, 1951; Dupias, 1985). En el conjunto de la cordillera predominan los sustratos silíceos en el centro y en la vertiente septentrional, mientras que las calizas resultan más abundantes en la zona más meridional central y occidental, y los sectores orientales muestran abundantes ambos tipos de sustrato. Los depósitos de yeso con vegetación especializada quedan acantonados en el límite meridional, ya en contacto con la Depresión del Ebro. Hay que señalar la acidificación de los suelos por lavado de bases que se observa de forma generalizada en amplias superficies calizas con marcada pluviosidad.

Respecto al clima, la proximidad a los mares Cantábrico y Mediterráneo y la neta orientación Norte y Sur de gran parte de la cordillera da lugar a distintos tipos climáticos muy contrastados en su régimen de lluvias y temperaturas. De forma muy simplificada (Creus, 1982; Izard, 1985) se pueden reconocer los climas de influencia oceánica con temperaturas suaves y precipitaciones muy altas que penetran hasta el centro por la vertiente Norte y apenas alcanzan Aragón en la Sur. Los climas mediterráneos, con régimen térmico muy contrastado entre verano e invierno y precipitaciones anuales reducidas, aparecen sobre todo en el extremo oriental de la cadena (Rosellón, Ampurdán), en la parte más meridional del Pirineo central y en los Prepirineos. El clima del Pirineo catalán se diferencia por las marcadas precipitaciones de primavera y otoño y sequía estival muy amortiguada. Por último, los climas de carácter continental, alejados de las influencias marinas, predominan en el sector central de la cadena que incluye Andorra, siendo mucho más severos en la vertiente española y más atemperados en la francesa. En conjunto, las precipitaciones anuales -y su estacionalidad- varían entre los más de $2.500 \mathrm{~mm}$ en Guipúzcoa hasta los $500 \mathrm{~m}$ en las zonas más meridionales de Navarra y Aragón y las situadas en el extremo más oriental entre el Mediterráneo y los primeros contrafuertes montañosos del Rosellón y Ampurdán. A las variaciones climáticas ligadas al eje longitudinal de la cadena hay que añadir las altitudinales, que pueden resumirse en un descenso de $0,6^{\circ} \mathrm{C}$ en la temperatura media anual y un incremento de $100 \mathrm{~mm}$ de lluvia cada $100 \mathrm{~m}$ de ascenso en altitud. En consonancia, el período vegetativo disminuye con la altitud en ese mismo intervalo 11 días por año (Del Barrio et al., 1990). Por último, hay que señalar las variaciones a escala local impuestas por la topografía, que dan lugar a topoclimas y microclimas y, por ende, a la extraordinaria heterogeneidad del mosaico vegetal.

La estructura topográfica y los climas que acabamos de mencionar permiten distinguir tres sectores parejos en cada vertiente de los Pirineos: los dos del Oeste con fuerte influencia atlántica, otros dos en el extremo Este con 
influencia mediterránea (menor en el meridional) y los dos centrales, con predominio de clima continental y que albergan el núcleo del macizo y las cumbres más prominentes. Con límites más o menos coincidentes, está sectorización se ha utilizado en distintos catálogos de flora y descripciones de la vegetación (Braun-Blanquet, 1948; Villar, 1980; Vigo, 1976) y la adoptamos ahora (Figura 1) para el análisis de la distribución florística. Para la delimitación de los pisos de vegetación se ha seguido la zonificación considerada en Ninot et al. (2007).

\subsection{Criterio taxonómico y nomenclatural y selección de taxones}

La estructura taxonómica y la nomenclatura botánica del "Atlas de la Flora vascular de los Pirineos" (http:// florapirineos.ipe.csic.es) sigue, en gran parte de las familias, el de Flora iberica (Castroviejo et al., 1986-2015), Flora Gallica-Flore de France (Tison \& De Foucault, 2014), Flora europea Tutin et al., (1964-1980) y el índice sinonímico de Kerguélen (1993). En casos concretos, indicados en dicho atlas, se ha seguido el criterio de distintas monografías o el de algunos catálogos regionales (Aizpuru et al., 1999; Bolòs \& Vigo, 1984-2001; Lorda, 2001 y 2013; Villar et al., 1997-2001).

Se han tenido en cuenta las plantas autóctonas de presencia reciente, comprobada en los Pirineos con los rangos de especie y subespecie, que son los que se muestran en los distintos listados y tienen ficha y mapa de distribución en el mencionado Atlas. En los géneros que muestran reproducción apomíctica y en otros que han sido objeto de taxonomía inflacionaria (Alchemilla, Armeria, Hieracium, Taraxacum, Festuca), no se han considerado los taxones de identificación muy incierta, ya que sus citas arrastran numerosos errores en sus áreas de distribución y preferencias ambientales. No se han considerado tampoco los híbridos interespecíficos. En los distintos apartados de los resultados se señala el número de taxones analizados en cada caso, entendiéndose que para el resto no se disponía de la información oportuna.

Para definir los intervalos altitudinales ocupados por las plantas, se han considerado los rangos en que viven de forma preferente, excluyendo las altitudes mínimas y máximas que hemos juzgado como "extraordinarias", por haberse observado en una o en un número muy reducido de localidades y que figuran en el atlas en apartados separados. La abundancia media para cada planta se ha calculado a partir de la categoría asignada en la ficha de cada taxón como "criterio de experto", que combina de forma subjetiva la abundancia de poblaciones y de los individuos que las conforman. Otra medida de la abundancia -su amplitud territorial- se ha obtenido a partir del número de cuadrículas en que se encuentra cada planta, sin considerar el número ni el tamaño de sus poblaciones. El número de citas que sustenta esta información, y que ha servido para la elaboración de mapas del "Atlas", es de casi dos millones.
Los grupos corológicos y las formas biológicas se han agrupado en categorías que permitieran su interpretación y comparación con otros territorios. Los hábitats se han agrupado igualmente a partir de una primera clasificación más detallada basada en las unidades CORINE (Devillers et al., 1991) utilizadas en el atlas digital y posteriormente reagrupadas en categorías más generales. La naturalidad de los hábitats, considerada como una medida inversa al grado de intervención humana, se ha valorado a partir de la clasificación del hábitat prioritario ocupado por cada planta en las respectivas series de vegetación (Géhu \& Géhu-Franck, 1980; Loidi, 1994).

Por último, hay que señalar que el avance en el conocimiento de la flora del territorio por la adquisición de nuevas citas florísticas da lugar a correcciones y modificaciones en los valores asignados a la distribución regional y altitudinal y, a veces, a la abundancia. Por tanto, las cifras absolutas que presentamos en los resultados no pueden considerarse definitivas, aunque, debido al alto número de taxones, dichos cambios no afecten sustancialmente a los resultados mostrados como frecuencias.

\subsection{Análisis de datos}

La comparación de distribuciones de la corología, formas biológicas y amplitud altitudinal entre la flora de los distintos sectores y la de las plantas comunes respecto al total, se ha hecho mediante el tests Chi-cuadrado. La relación entre el número de taxones, los intervalos altitudinales y su superficie se ha evaluado mediante el coeficiente Rho de Spearman.

\section{Resultados}

\subsection{Diversidad y distintos estatus de la flora de Pirineos}

La Flora de los Pirineos reúne 4.341 taxones, de los que 3.838 son autóctonos y 503 son plantas alóctonas naturalizadas o asilvestradas, aunque esta última cifra resulta sólo orientativa por el incesante aumento de estas plantas, sobre todo en los ambientes más humanizados. Entre la flora autóctona, 3.652 taxones se encuentran actualmente localizados en el territorio y muchas de sus poblaciones están referenciadas con bastante exactitud (la gran mayoría con citaciones de, al menos, $1 \mathrm{~km}^{2}$ de precisión). Otras 51 plantas del territorio han sido citadas hasta la década de los setenta del siglo pasado, y cuentan con el aval de ejemplares de herbario, pero su presencia actual no está comprobada. De otras 68 plantas citadas en distintas publicaciones no hay referencia de herbario ni conocemos localidades y, por tanto, quedan pendientes de comprobación, aunque su presencia en el territorio resulta muy verosímil. Por el contrario, 44 plantas citadas del territorio las consideramos erróneas por su área de distribución y sus requerimientos ecológicos. Por último, otras 23 plantas también citadas en Pirineos, se conocen de localidades muy próximas pero resta por constatar su presencia en el territorio de estudio. 


\subsection{Distribución taxonómica}

Los 3.652 taxones autóctonos, y con presencia reciente comprobada, corresponden a 3.437 con rango específico y 215 subespecífico. Helechos, isoetes y licopodios, (Pteridofitos Subdivision PTERIDOFITINOS) suman 95 taxones; entre las fanerógamas (Espermatofitos; Subdivision SPERMATOFITINOS) hay 19 coníferas (Clase Gimnospermas), y entre las plantas con flor (Clase Angiospermas) 2.818 taxones son dicotiledóneas (subclase Dicotiledoneas) y 720 monocotiledóneas (subclase Monocotiledoneas).

La flora de los Pirineos se agrupa en 145 familias (el $77 \%$ de las de toda la Península Ibérica); casi una tercera parte de los taxones corresponde a las familias Asteraceae (15\%), Poaceae (8\%) y Fabaceae (7\%). Respecto a los géneros, están representados 857 (aproximadamente el $64 \%$ de la Flora ibérica), de los cuales únicamente dos son endémicos (Borderea y Xatardia).

\subsection{Distribución territorial}

La Tabla 1 incluye el número de plantas de las divisiones administrativas de los Pirineos y muestra una alta correlación con la superficie $\left(\mathrm{R}^{2}=0,74 ; \mathrm{p}<0,001\right)$, aunque cabe destacar que Andorra, con menos del 1\% de la superficie, tiene el $38 \%$ de las plantas y el sector pirenaico del País Vasco, con menos del 5\% del territorio, alberga la mitad de la flora. Cataluña (24\% de la superficie de Pirineos) y Aragón (21\%) muestran la mayor representación de la flora ( 81 y $71 \%$ respectivamente).

La Figura 1 muestra los taxones presentes en cada sector geográfico de los Pirineos. Todos los sectores albergan más del $50 \%$ de la flora y ninguno sobrepasa el $76 \%$. Entre vertientes, los sectores meridionales son nota- blemente más ricos que los septentrionales. Por vertientes, el $85 \%$ de la flora vascular, 3.100 taxones, se encuentra en la Norte y el 95\%, 3.457 taxones, en la Sur; 2.928 taxones están en ambas vertientes, 176 se encuentran exclusivamente en la Norte y 532 exclusivamente en la Sur.

\subsection{Distribución altitudinal}

La Figura 2 muestra la distribución de plantas en el gradiente altitudinal de los Pirineos. Entre los 300 y $1.400 \mathrm{~m}$ de altitud, todos los intervalos de $100 \mathrm{~m}$ albergan más del 50\% de la flora. A partir de los $1.500 \mathrm{~m}$ de altitud se observa una disminución bastante uniforme del número de taxones que, por encima de los $2.000 \mathrm{~m}$, se reduce a 800 , por encima de $2.500 \mathrm{~m}$ a 239 y por encima de $3.000 \mathrm{~m}$ a 112 .

Aunque el número de plantas disminuye con la altitud por encima de los $1.300 \mathrm{~m}$, la densidad (número de taxones dividido por la superficie de cada intervalo de $100 \mathrm{~m}$ ) muestra una estrecha variación -entre 0,8 y 1,2 taxones/ $\mathrm{km}^{2}$-, entre esa altitud y los $2.700 \mathrm{~m}$, pero por encima de esa altitud se observa un fuerte incremento en cada intervalo de $100 \mathrm{~m}$ que alcanza valores de $6,11,14,38$ taxones $/ \mathrm{km}^{2}$ sobre los $2.900 \mathrm{~m}, 3.000 \mathrm{~m}, 3.100 \mathrm{~m}$ y $3.200 \mathrm{~m}$, respectivamente. No obstante, en el conjunto del gradiente altitudinal, el número de taxones en cada intervalo de $100 \mathrm{~m}$, muestra una alta correlación con su superficie $\left(\mathrm{R}^{2}\right.$ $=0,929, \mathrm{p}<0,001)$.

Por pisos de vegetación, el $87 \%$ de la flora está representada en el piso montano, con abundancias similares en el montano superior e inferior $(73$ y $71 \%$, respectivamente). En el piso basal (por debajo de los $500 \mathrm{~m}$ ), viven el $61,5 \%$; en el piso subalpino (hasta los $2.300 \mathrm{~m}$ ) el 33\%; en el alpino (entre 2.300 y $2.800 \mathrm{~m}$ ) el $17 \%$ y en el subnival (por encima de $2.800 \mathrm{~m}$ ) el $3 \%$.

Tabla 1: Número total de plantas, porcentaje, taxones exclusivos de una región, superficie en el territorio de estudio, intervalo altitudinal de $100 \mathrm{~m}$ y amplitud altitudinal de las divisiones administrativas de los Pirineos.

Table 1: Total number of plants, percentage, number of plants occurring in a single region, surface in the study area, highest and lowest altitude and $100 \mathrm{~m}$ altitudinal range of the different administrative regions of the Pyrenees.

\begin{tabular}{|c|c|c|c|c|c|c|}
\hline & $\begin{array}{l}\text { n. }{ }^{\circ} \text { total } \\
\text { Taxones }\end{array}$ & $\begin{array}{c}\text { Taxones } \\
(\%)\end{array}$ & $\begin{array}{l}\text { n. }{ }^{0} \text { taxones } \\
\text { exclusivos }\end{array}$ & $\begin{array}{c}\text { Superficie } \\
\left(\mathbf{k m}^{2}\right)\end{array}$ & $\begin{array}{c}\text { Intervalo } \\
\text { altitudinal }\end{array}$ & $\begin{array}{l}\text { Amplitud } \\
\text { altitudinal }\end{array}$ \\
\hline Andorra & 1393 & 38,2 & 6 & 451,7 & $800-2900$ & 2100 \\
\hline Alto Garona & 1653 & 45,4 & 4 & 1419,9 & $200-3200$ & 3000 \\
\hline Ariège & 1774 & 48,7 & 7 & 3993,4 & $200-3100$ & 2900 \\
\hline Pirineos Atlánticos & 1790 & 49,1 & 11 & 3697,4 & $0-2900$ & 2900 \\
\hline Altos Pirineos & 1848 & 50,7 & 9 & 3103,8 & $200-3300$ & 3100 \\
\hline País Vasco & 1848 & 50,7 & 16 & 2441,1 & $0-1600$ & 1600 \\
\hline Aude & 2057 & 56,4 & 16 & 2648,1 & $0-2500$ & 2500 \\
\hline Navarra & 2339 & 64,2 & 19 & 6658,1 & $20-2400$ & 2400 \\
\hline Pirineos Orientales & 2529 & 69,4 & 37 & 3225,9 & $0-2900$ & 2900 \\
\hline Aragón & 2591 & 71,1 & 71 & 10803,3 & $200-3400$ & 3200 \\
\hline Cataluña & 2958 & 81,2 & 98 & 12263,9 & $0-3100$ & 3100 \\
\hline
\end{tabular}




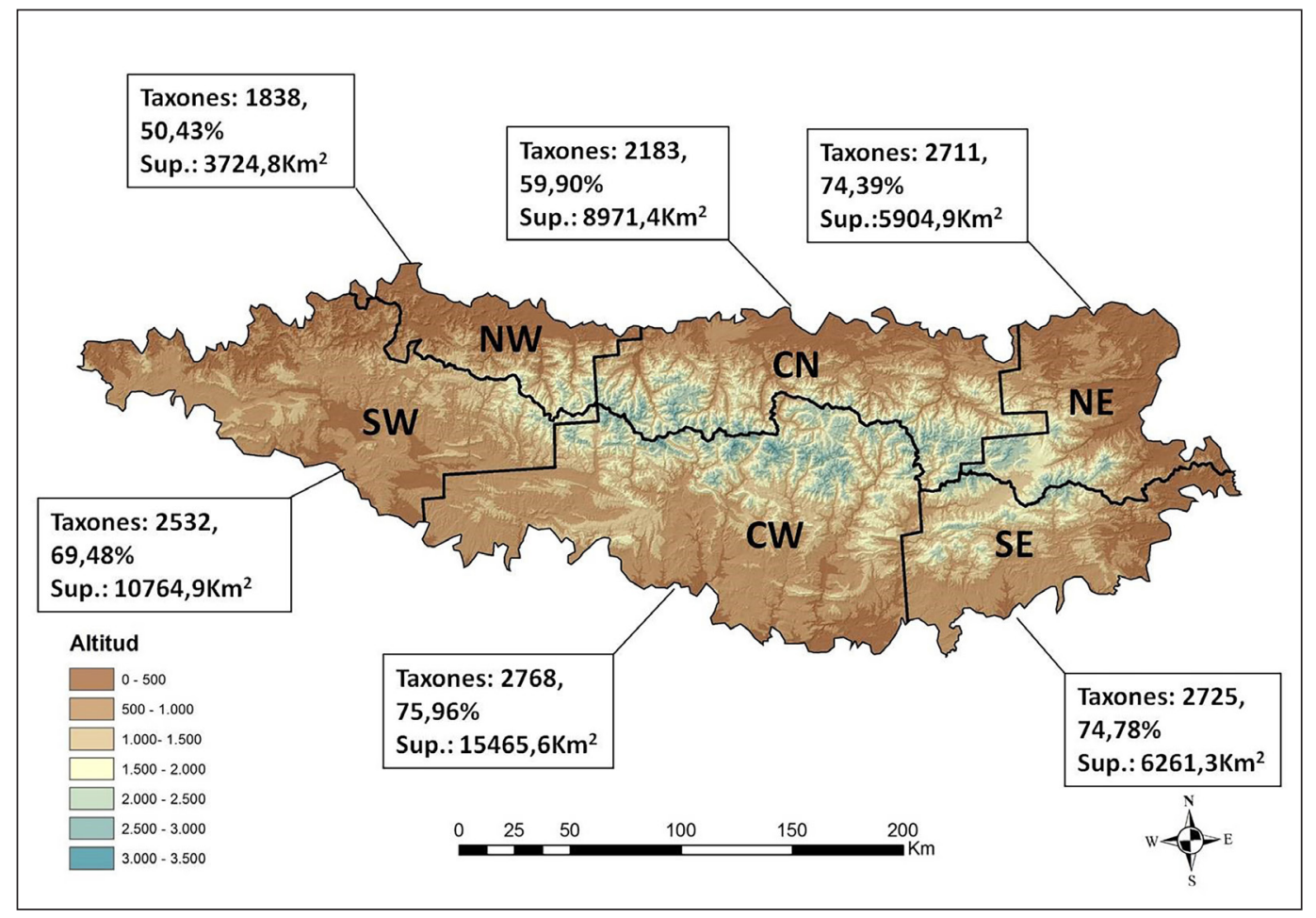

Figura 1: Mapa del área de estudio con los seis sectores geográficos de los Pirineos, el porcentaje del total de la flora y la superficie de cada sector.

Figure 1: Map of the study area with the 6 geographical sectors, the \% of the total flora and the surface in $\mathrm{km}^{2}$ of each sector.

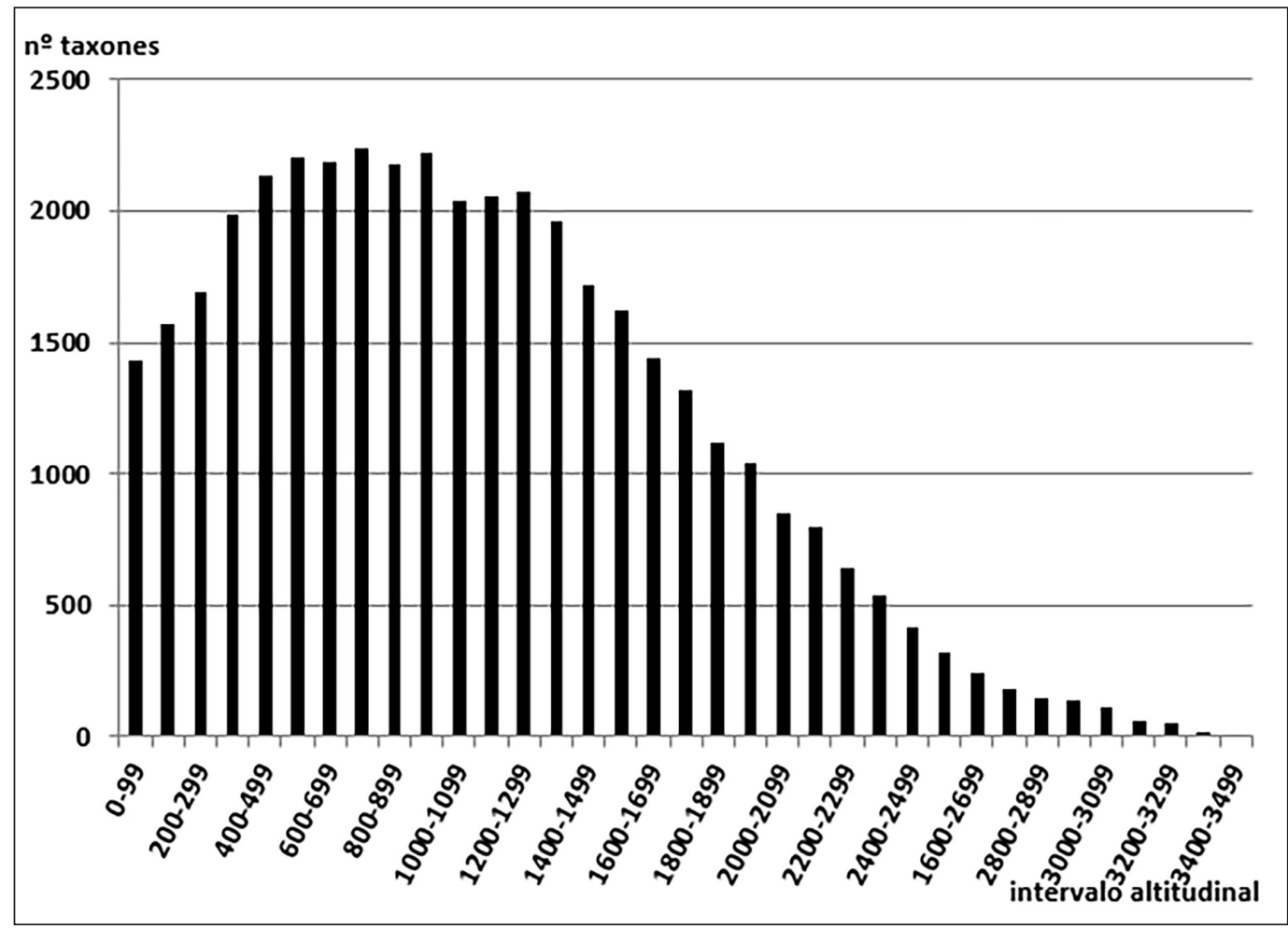

Figura 2: Número de plantas en cada intervalo altitudinal de $100 \mathrm{~m}$.

Figure 2: Number of plants in each 100 m altitudinal range. 


\subsection{Rango altitudinal}

Los límites altitudinales superior e inferior en que se encuentran las plantas definen su "amplitud altitudinal" que muestra la siguiente distribución en el total de la flora de Pirineos: el 16,6\% de las plantas viven en un rango menor de $500 \mathrm{~m}$ de altura; el $28 \%$ en un rango de $500-1.000 \mathrm{~m}$; el $33,5 \%$ en un rango de $1.000-1.500 \mathrm{~m}$, el $16,1 \%$ en un rango de 1.500 a 2.000 ; el $4,6 \%$ en un rango de 2.000 a 2.500 y un $0,6 \%$ (23 plantas) de 2.500 a $3.000 \mathrm{~m}$, lo que supone que pueden encontrarse casi a cualquier altitud de la cordillera.

$\mathrm{Si}$ analizamos la amplitud altitudinal en los diferentes hábitats (Tabla 2), únicamente encontramos diferencias significativas respecto al conjunto en la flora de los humedales $(\mathrm{p}<0,01)$, que muestran mayor amplitud altitudinal, y en la de las comunidades antrópicas $(\mathrm{p}<0,01)$ que, por el contrario, presentan intervalos altitudinales más estrechos. En cuanto a las formas biológicas, se observan diferencias significativas respecto al total en los hemicriptófitos ( $p<0,001)$, que muestran mayor amplitud altitudinal, y los terófitos $(\mathrm{p}<0,001)$ y fanerófitos $(\mathrm{p}<0,01)$ con menor amplitud. En cuanto a la corología, se observan diferencias significativas respecto al total de la flora en todos los grupos ( $p<0,001)$, excepto en las boreoalpinas. Las plantas eurosiberianas y las de amplia distribu- ción muestran mayor amplitud altitudinal que el total de la flora y menor las mediterráneas y endémicas.

\subsection{Corología y límites de distribución}

La corología de la flora pirenaica está encabezada por las plantas de distribución eurosiberiana (35\%) y mediterránea (32\%), seguidas por las de "amplia distribución" -pluriregionales y subcosmopolitas- (14\%) y por los orófitos alpinos (10\%). Las plantas endémicas constituyen el $5,5 \%$ y las boreoalpinas el 3,5\%.

Ambas vertientes de Pirineos (Figura 3) muestran espectros corológicos significativamente diferentes $(\mathrm{p}<0,001)$. La comparación de los distintos sectores revela diferencias acusadas (Tabla 3). Los sectores Norte occidental y central tienen mayor abundancia de plantas eurosiberianas $(49,4 \mathrm{y}$ $46,6 \%$, respectivamente) y menor de las mediterráneas (13,3 y 15,8$)$ que los respectivos sectores Sur $(43,1$ y 37,6 de eurosiberianas frente a 26,6 y 27,5 de mediterráneas). En los sectores orientales, esta diferencia se reduce al 1\%. Si atendemos al número de taxones, puede verse que ambos sectores orientales muestran un número similar de plantas mediterráneas y eurosiberianas, mientras que los dos sectores occidentales tienen cifras muy diferentes en ambos grupos.

Tabla 2: Amplitud altitudinal (en porcentaje) de las plantas según el hábitat que ocupan, su forma biológica y su corología. Table 2: Altitudinal range (in percentage) of Pyrenean plants according to their habitat occurrence, life-form and chorology.

\begin{tabular}{|c|c|c|c|c|c|c|}
\hline Rango (m) & & $0-499$ & 500-999 & 1000-1499 & 1500-1999 & $>2000$ \\
\hline \multirow{7}{*}{ Hábitat } & Pastos & 14,8 & 36,4 & 29,6 & 13,9 & 5,3 \\
\hline & Humedales & 19,5 & 32,9 & 22 & 18,9 & 6,7 \\
\hline & Roquedos y gleras & 22,1 & 27,4 & 31,7 & 14,5 & 4,3 \\
\hline & Matorrales & 16,9 & 30,1 & 33,4 & 15,8 & 3,8 \\
\hline & Com. antrópicas & 16,5 & 35,5 & 34,2 & 11,6 & 2,2 \\
\hline & Bosques & 12,7 & 33,1 & 29,3 & 19,3 & 4,6 \\
\hline & Total & 16,9 & 33,2 & 29,6 & 15,5 & 4,8 \\
\hline \multirow{7}{*}{ For. Biológicas } & Hemicriptófito & 16 & 30,4 & 30,6 & 16,8 & 6,2 \\
\hline & Terófito & 23,9 & 38 & 26,4 & 9,6 & 2,1 \\
\hline & Caméfito & 23,1 & 30,7 & 28,2 & 14,3 & 3,7 \\
\hline & Geófito & 22,1 & 29,2 & 24,8 & 18,4 & 5,5 \\
\hline & Fanerófito & 14,5 & 42,1 & 29,8 & 12,4 & 1,2 \\
\hline & Hidrófito & 32,6 & 33,7 & 20,6 & 9,8 & 3,3 \\
\hline & Total & 19,7 & 32,7 & 28,4 & 14,7 & 4,5 \\
\hline \multirow{7}{*}{ Corologia } & Alpinas & 12,4 & 40,2 & 33,5 & 10,1 & 3,7 \\
\hline & Boreoalpinas & 18 & 39,3 & 29,5 & 10,6 & 2,4 \\
\hline & Endémicas & 17,6 & 46 & 25,5 & 10,2 & 0,6 \\
\hline & Eurosiberianas & 11,7 & 26,8 & 31,2 & 22,7 & 7,4 \\
\hline & Mediterráneas & 28,6 & 37,9 & 24,5 & 7,5 & 1,4 \\
\hline & Amplia Distribución & 13,7 & 25,7 & 32,2 & 20,6 & 7,7 \\
\hline & Total & 18,5 & 33 & 28,9 & 15 & 4,5 \\
\hline
\end{tabular}


Tabla 3: Distribución de grupos corológicos en los seis sectores de Pirineos (valores absolutos y entre paréntesis porcentajes). Table 3: Distribution of chorological groups in the six geographic sectors of the Pyrenees (absolute values and, in brackets, percentages).

\begin{tabular}{|l|c|c|c|c|c|c|}
\hline & Oriental N & Oriental S & Central N & Central S & Occiden. N & Occiden. S \\
\hline Alpinas & $259(10,1)$ & $247(9,4)$ & $271(13,2)$ & $293(11,4)$ & $233(13)$ & $230(9,2)$ \\
\hline Amplia distrib. & $398(15,5)$ & $410(15,6)$ & $332(16,2)$ & $373(14,5)$ & $291(16,2)$ & $387(15,5)$ \\
\hline Boreoalpinas & $94(3,7)$ & $89(3,4)$ & $105(5,1)$ & $103(4)$ & $78(4,4)$ & $65(2,6)$ \\
\hline Endemicas & $82(3,2)$ & $102(3,9)$ & $65(3,2)$ & $128(5)$ & $65(3,6)$ & $74(3)$ \\
\hline Atlánticas & $87(3,4)$ & $88(3,3)$ & $94(4,6)$ & $74(2,9)$ & $110(6,1)$ & $146(5,8)$ \\
\hline Eurosiberianas & $911(35,5)$ & $910(34,6)$ & $861(42)$ & $889(34,7)$ & $776(43,3)$ & $933(37,3)$ \\
\hline Mediterráneas & $736(28,7)$ & $781(29,7)$ & $324(15,8)$ & $704(27,5)$ & $238(13,3)$ & $664(26,6)$ \\
\hline
\end{tabular}

Las plantas de distribución atlántica (120 taxones, el $3,3 \%$ del total, que se han incluido dentro de las eurosiberianas en la Tabla 2) son, en frecuencia, menos abundantes en la vertiente meridional (112 taxones, el 3,2\%) que en la septentrional (103 taxones, el 4,9\%) y disminuyen de Oeste hacia el Este en ambas vertientes, aunque de manera mucho más brusca en la vertiente Sur: 105 en el sector occidental, 50 en el central y 46 en el oriental.

La representación de plantas alpinas y boreoalpinas es, en porcentaje, ligeramente mayor en la vertiente septentrional aunque atendiendo al número de taxones, la mayor abundancia se observa en el sector central Sur, coincidiendo con la zona de mayor elevación altitudinal de la cordillera. En total, los sectores occidental y central muestran diferencias significativas en los espectros corológicos de ambas vertientes $(p<0,001)$, mientras que los sectores orientales no son significativamente diferentes.

En los Pirineos encuentran su límite de distribución 730 plantas (el 20\% del total); 385 su límite sur (70 son boreoalpinos, 163 orófitos alpinos, 138 eurosiberianos y 4 de amplia distribución). En sentido contrario, 345 taxones muestran en los Pirineos su límite septentrional que en su

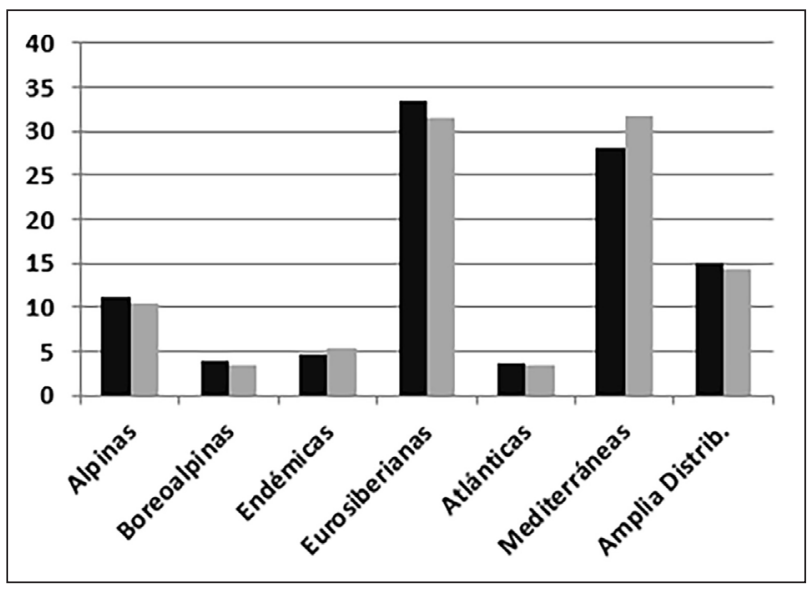

Figura 3: Espectro corológico en ambas vertientes de los Pirineos (Pirineo N: columnas negras, Pirineo Sur: columnas grises).

Figure 3: Chorological spectrum in both Pyrenean slopes (black columns: North Pyrenees; green columns: South Pyrenees). mayor parte, 270 taxones, son mediterráneos, 6 atlánticos y el resto europeas o de amplia distribución.

\subsection{Distribución de formas biológicas}

El 44\% de la flora de los Pirineos son hemicriptófitos, el $20,4 \%$ terófitos, el 14,2\% caméfitos, el 12,2\% geófitos, el $6,6 \%$ fanerófitos ( $4 \%$ nanofanerófitos y 2,6\% macrofanerófitos), el 2,4\% hidrófitos y el $0,2 \%$ epífitos. El espectro de formas biológicas varía notablemente con la altitud (Figura 4). Las tendencias principales son el aumento gradual de los caméfitos, que pasan de representar el 12\% por debajo de $1.500 \mathrm{~m}$ a más del $30 \%$ por encima de los $3.000 \mathrm{~m}$, y de los hemicriptófitos que pasan de menos del $40 \%$ bajo los $1.000 \mathrm{~m}$ a más del $60 \%$ sobre los $2.000 \mathrm{~m}$. En sentido contrario, los terófitos pasan de alrededor del $30 \%$ bajo los $1.000 \mathrm{~m}$ al $8 \%$ sobre los $2.000 \mathrm{~m}$ y el $3 \%$ sobre los $3.000 \mathrm{~m}$. Los geófitos se mantienen muy constantes en el gradiente altitudinal hasta los $2.500 \mathrm{~m}$ y descienden a la mitad sobre los $3.000 \mathrm{~m}$. Por último, fanerófitos e hidrófitos descienden también con el aumento de la altitud.

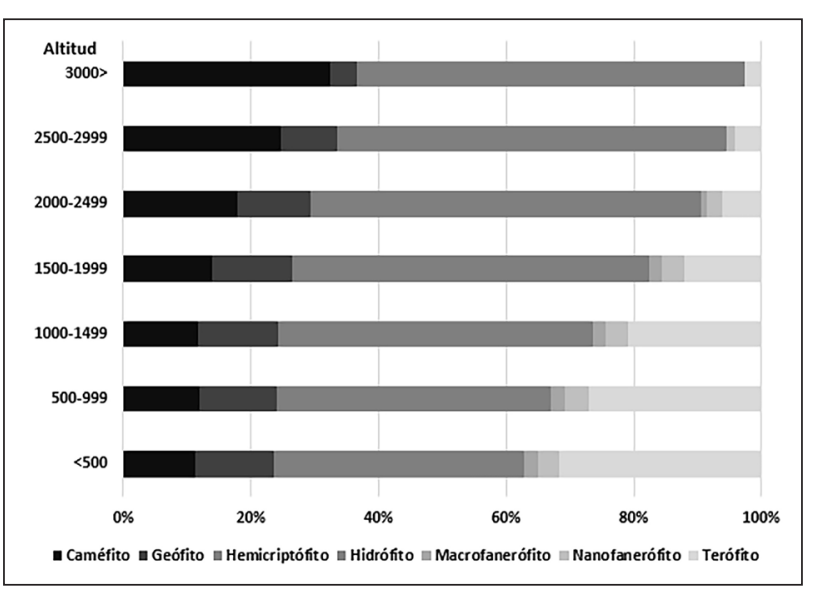

Figura 4: Variación de las formas biológicas de la flora en el gradiente altitudinal de los Pirineos.

Figure 4: Variation of the Life-form spectrum along the altitudinal gradient of the Pyrenees. 


\subsection{Preferencia edáfica}

Las plantas basófilas (presentes en suelos carbonatados) suponen casi el 35\% del total de la Flora de los Pirineos. Las plantas acidófilas constituyen el 21,4\%, mientras el restante $43,5 \%$ puede considerarse "indiferente edáfica".

Al comparar los sectores (Figura 5) se aprecia una escasa diferencia entre ambos sectores orientales, mientras que en los sectores centrales y occidentales hay una mayor abundancia (alrededor del 5\%) de plantas acidófilas en los Norte que en los Sur y, viceversa, una similar mayor abundancia de las plantas basófilas en los sectores Sur que en los Norte. Dentro de las plantas basófilas pueden distinguirse alrededor de 90 taxones (el 2,5\% del total), que viven preferentemente en suelos con abundancia de sales (gipsófitos y halófitos) y que, excepto las propias de los hábitats litorales atlántico y mediterráneo, viven en su mayor parte en los sectores central y oriental Sur, sin apenas sobrepasar los $400 \mathrm{~m}$ de altitud y señalando los afloramientos salinos próximos a las cubetas endorreicas de la Depresión del Ebro.

\subsection{Hábitat y naturalidad de los hábitats}

Aunque algunas plantas se localizan en más de un hábitat (por ejemplo en claros forestales y en sus comunidades seriales arbustivas y herbáceas), si nos fijamos en los hábitats preferentes de cada planta (Figura 6) se observa que casi el $30 \%$ de la flora de los Pirineos se sitúa en comunidades de pastos. En el otro extremo, solo un 3,6\% se vincula a los ambientes litorales marinos y suelos salobres del interior que, por otra parte, ocupan superficies muy reducidas. Los humedales, incluyendo comunidades de ribera, fontinales y otros ambientes con suelo húmedo gran parte del año, albergan el 16\% de la flora. El resto de hábitats acogen una proporción similar (entre el 12-13\%) de plantas.

Por último, clasificando el grado de naturalidad de los hábitats en cuatro categorías, encontramos que un 13\% de

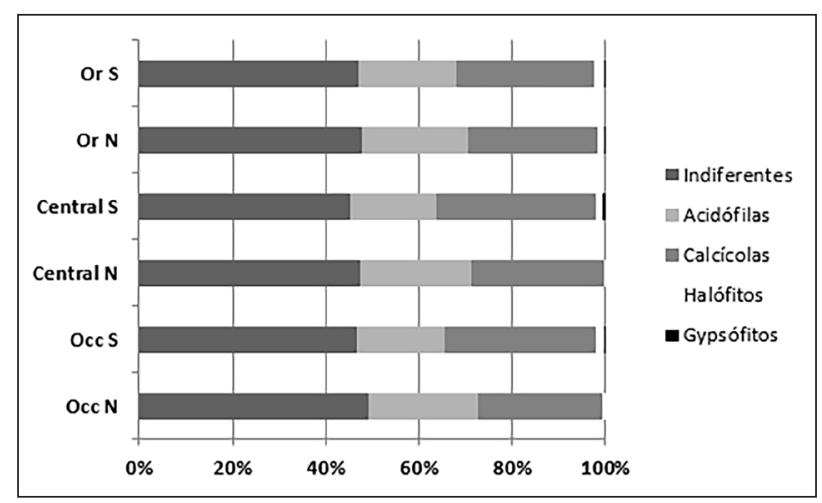

Figura 5: Distribución de la flora según su afinidad edáfica en los sectores de los Pirineos.

Figure 5: Flora distribution according their soil preference in the geographic sectors of the Pyrenees. la flora se encuentra preferentemente en hábitats de alta o muy alta naturalidad (principalmente en roquedos, pastos y matorrales de alta montaña y bosques maduros), el 33\% en hábitats de alta naturalidad, (pastos, matorrales y bosques con moderada intervención humana), el $30 \%$ en los de media naturalidad y el $24 \%$ en los de baja naturalidad (ambientes muy alterados por una fuerte intervención humana que incluyen zonas urbanas, cultivos, matorrales y pastos degradados).

\subsection{Abundancia y rareza}

La Figura 7 muestra la distribución de la flora pirenaica por su abundancia, calculada como el valor medio - para 3.622 taxones- de las categorías (muy rara, rara, escasa, frecuente, común y muy común) asignadas en el

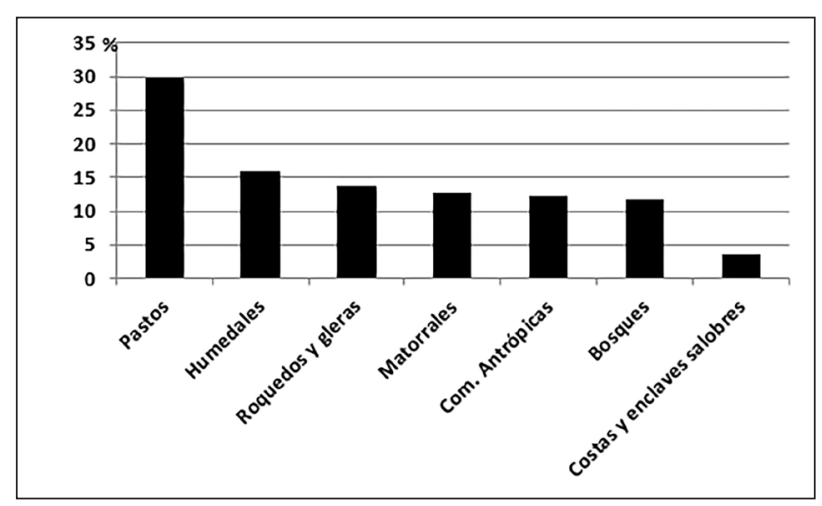

Figura 6: Distribución de la flora de los Pirineos en los principales tipos de hábitats.

Figure 6: Pyrenean flora distribution in the main type of hábitats.

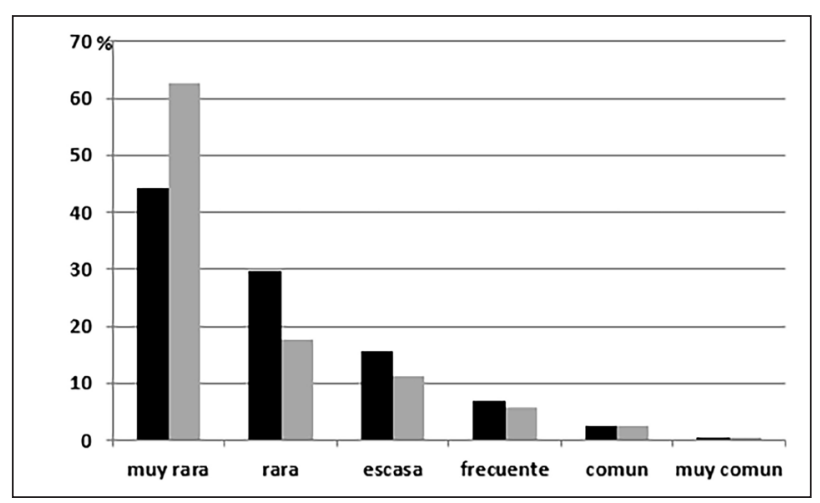

Figura 7: Distribución de la flora pirenaica según su abundancia. Las columnas en negro señalan la abundancia media en los sectores en que está presente cada planta y las columnas grises la abundancia ponderada en el conjunto de los Pirineos.

Figure 7: Distribution of Pyrenean plants according their abundance. Black columns point out the average abundance considering only sectors where each plant occurs, and grey columns the abundance considering all sectors of the Pyrenees. 
"Atlas" para cada planta en cada sector en que se encuentra la planta y expresadas en categorías numéricas, (respectivamente de 1 a 6 ). Cerca del $75 \%$ de la flora pertenece a las categorías "raras" o "muy raras", mientras que apenas un $3 \%$ se consideran comunes o muy comunes. Si el valor medio de abundancia se pondera para todo el territorio (dividiéndolo por los seis sectores en que se ha asignado el valor de abundancia), se observa una mayor frecuencia de las plantas muy raras (que se incrementan del 44 al 63\%) y disminuye la del resto de categorías, excepto las comunes y muy comunes que permanecen con valores muy similares en ambos casos.

La distribución de la flora en los seis sectores geográficos del territorio muestra que el $35 \%$ de las plantas se encuentra representado en todos los sectores, mientras que las que ocupan uno, dos, tres, cuatro o cinco sectores, tienen una proporción similar, entre el 12 y el $15 \%$. En cuanto a la representación territorial por el número de cuadrículas ocupadas, un $17 \%$ de las plantas se localiza en 10 o menos cuadrículas, es decir en menos del $0,02 \%$ del territorio, el $28 \%$ ocupa entre 11 y 50 cuadrículas, el $29 \%$ entre 50 y 150 , el $19 \%$ entre 151 y 300 , y un $6,6 \%$ está en más de 300 cuadrículas (que suponen más del $60 \%$ del territorio).

La flora más común, formada por 354 plantas $(10 \%$ del total) que están en más de 250 cuadrículas de 10 x 10 $\mathrm{km}$, muestra diferencias significativas respecto al conjunto de la flora en su corología, su espectro de formas biológicas y su hábitat preferente ( $\mathrm{p}<0,001$ en los tres casos). Destacan en este grupo por su abundancia las plantas eurosiberianas y las de amplia distribución, los hemicriptófitos, y las plantas de bosques, matorrales y comunidades antrópicas. La distribución y características de la flora "rara" se describe en otro artículo incluido en este mismo número de la revista Pirineos.

\section{Discusión y conclusiones}

La flora vascular de los Pirineos, con un total de 3.652 plantas autóctonas, representa más del $40 \%$ de la flora ibérica (Castroviejo, 2002) y más del 60\% de la de flora de Francia (Tison \& de Foucault, 2014). Estas cifras sitúan a la cordillera pirenaica como el primer centro de diversidad de la Península y el segundo de Europa occidental, tras los Alpes, que cuenta con 4.491 plantas (especies y subespecies), aunque incluyen en dicha cifra aproximadamente un $10 \%$ de xenófitos (Aeschimann et al., 2004). Sin embargo, la riqueza florística de los Pirineos aumenta considerablemente si consideramos que su superficie es menos de un tercio de la de la cordillera alpina, que abarca unos $170.000 \mathrm{~km}^{2}$. En los Pirineos septentrionales está representada el $85 \%$ del total de la flora pirenaica ( $95 \%$ en la vertiente meridional), lo que sugiere que la diversidad florística de los Pirineos de Francia es muy notable si consideramos la superficie que ocupan (solo un $35,5 \%$ del total) y su topografía menos compleja, por la presencia de las cumbres más elevadas y las Sierra Exteriores en la vertiente meridional.
La flora pirenaica muestra una curva similar a la descrita en otras montañas en cuanto a la distribución en el gradiente altitudinal, aunque la máxima diversidad no se ajusta con las altitudes intermedias como se ha descrito en otras cordilleras (Rahbek, 1995; Grytnes \& Vetaas, 2002; Oomen \& Shanker, 2005), sino que aparece desplazada hacia la zona más baja, mostrando el máximo entre los 300 y $1.300 \mathrm{~m}$ de altitud. El modelo "Mid-Domain effect", que preconiza la máxima diversidad en altitudes intermedias, ha sido cuestionado cuando se generaliza a gradientes con una influencia muy heterogénea de factores ambientales y rangos de frecuencia de distribución ("range size frecuency distribution", Hawkins et al., 2005). La falta de datos similares en otras cadenas montañosas del ámbito alpino impide una sólida comparación con los Pirineos, pero cabe destacar que entre los 300 y $1.400 \mathrm{~m}$ de altitud la mitad de la flora está presente en cada intervalo altitudinal de $100 \mathrm{~m}$ y hasta los $1.700 \mathrm{~m}$ (en la transición de los pisos montano y subalpino, que señala el límite de la presión humana más intensa en los últimos siglos) se mantiene el $40 \%$ la diversidad florística. Estos datos permiten analizar los distintos tipos de patrones (unimodales, multimodales, etc.) que emergen en el amplio abanico de características climáticas, factores ambientales y usos humanos presentes en los Pirineos, y así contribuir al estudio de los múltiples mecanismos que subyacen a la variación de la diversidad en los gradientes altitudinales, todavía poco conocidos y a veces divergentes (Pimm \& Brown, 2004, Rahbek, 1995).

La amplitud altitudinal que ocupan las plantas constituye un aspecto relevante en relación con la capacidad de migración de sus poblaciones en territorios montañosos y su posible vulnerabilidad frente al cambio climático (Engler et al., 2009 y 2011). Aunque tampoco en este aspecto tenemos datos comparativos de otras cordilleras, cabe destacar que más de la mitad de la flora pirenaica se extiende en rangos de, al menos, $1.000 \mathrm{~m}$ de altitud. Este amplio rango podría considerarse, de forma simplista, como una variable que permitiría cierta movilidad para las migraciones altitudinales frente al cambio climático, pues abarcaría más de $6^{\circ} \mathrm{C}$ de temperatura media anual y entre 500 y $1.000 \mathrm{~mm}$ de precipitación. Sin embargo, las marcadas variaciones climáticas asociadas a la microtopografía, entre ellas las de la cubierta nival (López Moreno et al., 2005), exige analizar las peculiaridades ambientales de los enclaves ocupados por cada planta en su emplazamiento altitudinal para modular su área de distribución potencial.

Respecto a la corología, la altitud más elevada que muestran los Pirineos centrales se traduce en una mayor presencia de taxones alpinos y boreoalpinos en dicho sector. Sin embargo, a pesar de que la mayor parte de las cumbres más altas se sitúan en la vertiente meridional (Dupias, 1985), el número de taxones de esos grupos corológicos es muy similar en ambas vertientes. Por otra parte, estas plantas son más abundantes en el extremo oriental que en el occidental, lo que podría traducir la dirección y sentido predominantes - de Norte a Sur y de Oeste a Estede las rutas migratorias seguidas por esos grupos florísti- 
cos durante las glaciaciones. En el contraste entre vertientes sobresale la presencia de flora mediterránea, para la que los Pirineos parecen constituir una potente barrera en su sector central, que se atenúa en el occidental y, sobre todo, en el oriental. Sin embargo, las plantas eurosiberianas muestran una presencia similar en ambas vertientes o, incluso, son más abundantes en la meridional. Resulta también muy destacable y diferencial la representación de flora atlántica en la vertiente septentrional, que se corresponde con la mayor penetración oceánica, que ya ha sido resaltada por distintos autores (Montserrat-Martí \& Montserrat-Martí, 1984; Dupias, 1988; Dupont, 2015). En resumen, los sectores orientales son muy similares en su corología florística, a pesar de cierta disimetría paisajística entre Sur y Norte por la mayor humedad proveniente del Mediterráneo en los Pirineos catalanes (Vigo, 1976). Este parecido apunta a una mayor facilidad para la migración de las plantas, sobre todo las mediterráneas, entre ambas vertientes. Por el contrario, en los sectores occidentales y centrales el efecto barrera de la cadena montañosa se acentúa cuando analizamos los grupos biogeográficos.

El patrón de abundancia/rareza de la flora de los Pirineos coincide con el que se ha descrito para muchas otras regiones (Gaston, 1994), de manera que las plantas comunes son notablemente más escasas que las raras en el conjunto del territorio.

La distribución de la flora por hábitats muestra un patrón similar al observado a escala regional para Aragón (García \& Gómez, 2007) con una presencia muy notable de la flora en los pastos y también, considerando la reducida superficie que ocupan, en los hábitats rocosos y en los humedales. En sentido opuesto, hay que señalar la escasa diversidad florística en los ambientes forestales. Estos resultados subrayan la necesidad de preservar los ecosistemas pastorales ligados a la ganadería extensiva para la conservación de la diversidad florística.

Respecto al grado de naturalidad de los hábitats, cabe destacar la diversidad florística asociada a ambientes con bajo valor de naturalidad, pues casi representan el doble de plantas de las que se encuentran en la categoría más alta. Se incluyen ahí buena parte de la flora segetal, con plantas que fueron banales e incluso invasivas hasta fechas recientes y muestran ahora un fortísimo declive por la intensificación de las prácticas agropecuarias y la proliferación de pesticidas. Los altos niveles de diversidad florística en ambientes deteriorados han sido ya descrito en otros territorios (Hodgson, 1986), aspecto que debe ser considerado en las políticas de conservación vegetal.

\section{Agradecimientos}

Los datos básicos de este trabajo se han elaborado en parte con la información recogida en el Atlas digital de la flora vascular de los Pirineos, subvencionado por Fondos FEDER de la UE, patrocinado por un Proyecto POCTEFA de la Comunidad de Trabajo de los Pirineos (CTP) y el Observatorio Pirenaico de Cambio Climático (OPCC). Los autores de las fichas de dicho atlas son (por orden alfabéti- co): C. Aedo, I. Aizpuru, J. Ascaso, C. Bergès, M. Doménech, O. Fernández, J.V. Ferrández, X. Font, J. Garmendia, D. Gómez, N. Ibáñez, B. Komac, F. Laigneau, M. Lorda, F. Martínez, J.M. Martínez, J. Molina, N. Montes, J.M. Montserrat, F. Muñoz, C. Navarro, N. Nualart, L. Oreja, J. Pedrol, J. Peralta, D. Pérez, C. Pladevall, J. Puente, A. Pujadas, S. Pyke, J.L. Remón, I. Soriano, J.M. Tison, L. Uriarte, P.M. Uribe-Echebarría, A. Valverde. Las instituciones participantes en el proyecto: IHOBE, CSIC (Instituto Pirenaico de Ecología, Jardín Botánico e Institut Botanic), Universitat de Barcelona, Universidad Pública de Navarra, Sociedad de Ciencias Aranzadi, Conservatoire Botanique Mediterranéen, Conservatoire Botanique des Hautes Pyrénées y CENMA de Andorra. En la elaboración de mapas y gráficos tenemos que agradecer la ayuda de Luis Calderón y Paz Erréa. El estudio se enmarca dentro del proyecto PERDIVER (Fundación BBVA).

\section{Referencias}

Aeschimann, D., Lauber, K., Moser, D.M. \& Theurillat, J.P., 2004. Flora alpina. 3 Vol. ISBN 2-7011-3899-X (1). Paris.

Aizpuru, I., Aseginolaza, C., Uribe-Echebarría, P., Urrutia, P. \& Zorrakin, I., 1999. Claves Ilustradas de la Flora del País Vasco y territorios limitrofes. Servicio central de publicaciones del Gobierno Vasco: 831 pp., Vitoria-Gasteiz.

Aseginolaza, C., Gómez, D., Lizaur, X., Montserrat, G., Morante, G., Salaverría, M. R.. Uribe-Echebarría, P. M. \& Alejandre, J. A., 1985. Catálogo florístico de Álava, Vizcaya y Guipúzcoa. Servicio de Publicaciones del Gobierno Vasco. Vitoria.

Asso, C. 1779. Synopsis stirpium indigenarum Aragoniae. Massiliae.

Asso, C., 1781. Mantissa stirpium indigenarum Aragoniae. Amsterodanum.

Bentham, M. 1826. Catalogue des Plantes indigènes des Pyrénées et du Bas Languedoc.

Bolòs Capdevilla, O. de., 1963. Botánica y Geografía. Memorias de la Real Academia de Ciencias y Artes de Barcelona. NN $^{\circ} 697$ Vol XXXIV. N 14: 443-481. Barcelona.

Bolòs, O. de \& Vigo, J., 1984-2001. Flora dels Països Catalans. 4 vols. Ed. Barcino. Barcelona.

Braun-Blanquet, J., 1948. La végétation alpine des Pyrénées Orientales. Monografías de la Estación de Estudios Pirenaicos e Instituto Español de Edafología, Ecología y Fisiología Vegetal, 9: 1-306.

Bubani, P., 1897-1902. Flora Pyrenaea per ordines naturales gradatim digesta. Vols. I-IV. Ed. Ulricus Hoeplius. Milán.

Castroviejo, S., Aedo, C., Benedi, C., Laínz, M., Muñoz Garmendia, F., Nieto Feliner, G. \& Paiva, J. (eds.), 1986-2015. Flora iberica. Real Jardín Botánico, C.S.I.C. 320 pp. Madrid. Consultado en edición digital: www.floraiberica.org

Castroviejo, S., 2002. Riqueza florística de la Península Ibérica $e$ islas Baleares. F.D. Pineda, J.M. de Miguel, M.A. Casado y J. Montalvo (Coordinadores-editores) La diversidad biológica de España. Pearson Educación S.A. Madrid.

Coste, H.J., 1901-1906. Flore descriptive et illustrée de la France de la Corse et des contrées limitrophes, 1901-1906. Klincksieck, Paris, 3 vols.

Creus, J., 1982. El clima del alto Aragón occidental. Monografías del Instituto de Estudios Pirenaicos, 109: 233 pp., Jaca.

Del Barrio, G., Creus, J. \& Puigdefábregas, J., 1990. Thermal Seasonality of the High Mountain Belts of the Pyrenees. Mountain Research and Development 10,(3): 227-233. https://doi.org/10.2307/3673602 
Devillers, P., Devillers-Terschuren, J.. \& Ledant, J.P., 1991. CORINE biotopes manual. Commission of the European Communities. Luxembourg

Dupias, G., 1985. Végétation des Pyrénées. Memoria de la Carte de Végétation de la France au 200.000e. Edition du CNRS : 209 pp., Paris.

Dupias, G., 1988. L'extension de la flore atlantique au versant Nord des Pyrénées. En: Homenaje a Pedro Montserrat. Monografías del Instituto Pirenaico de Ecología, número 4: 529-534, Jaca (Huesca).

Dupont, P., 2015. Les plantes vasculaires atlantiques, les pyrénéo-cantabriques et les éléments floristiques voisins dans la Péninsule ibérique et en France. Societé Botanique du centre-Ouest. $\mathrm{N}^{\mathrm{o}}$ spécial $45: 494 \mathrm{pp}$.

Engler, R., Randin, C.F., Vittoz, P., Czáka, T., Beniston, M., Zimmermann, N.E. \& A. Guisan, A., 2009. Predicting future distributions of mountain plants under climate change: does dispersal capacity matter?. Ecography, 32: 34-45. https://doi.org/10.1111/j.1600-0587.2009.05789.x

Engler, R., Randin, C., Thuiller, W., Dullinger, S., Zimmermann, N.E., Araújo, M.A., Pearman, P.B., Albert, C.H., Choler Ph., De Lamo, X., Dirnböck, T., Gómez-García, D., Grytnes, J.A., Heegard, E., Høistad, F., Le Lay, G., Nogués-Bravo, D., Normand, S., Piédalu, C., Puscas, M., Sebastià, M.T., Stanisci, A., Theurillat, J.P., Trivedi, M., Vittoz, P. \& Guisan, A., 2011. 21 st century climate change threatens mountain flora unequally across Europe. Global Change Biology, 17 (7): 23302341. https://doi.org/10.1111/j.1365-2486.2010.02393.x

Hodgson, J.G., 1986. Commonness and rarity in plants with special reference to the Sheffield flora Part I: The identity, distribution and habitat characteristics of the common and rare species. Biological Conservation 36(3): 199-252. https://doi.org/10.1016/0006-3207(86)90052-2

García, M.B. \& Gómez, D., 2007. Flora del Pirineo aragonés. Patrones espaciales de biodiversidad y su relevancia para la conservación. Pirineos, 162: 71-88. https://doi.org/10.3989/ pirineos.2007.v162.13

Gaston, K.J., 1994. Rarity. Chapman and Hall. London. https:// doi.org/10.1007/978-94-011-0701-3

Gaussen, H., 1953-1981. Catalogue-Flore des Pyrénées. In : Le Monde des Plantes ( $\left.{ }^{\circ} 293-410\right)$.

Gehú, J.M. \& Géhu-Franck, J., 1980. Essai d'evaluation biologique des milieux naturels. Examples littoraux. Semin. Phytosociologie appliquée: 76-93, Metz.

Gómez, D., Mateo, G., Mercadal, N., Montserrat, P. \& Sesé, J.A., 2005.- Atlas de la flora de Aragón. Instituto Pirenaico de Ecología y Departamento de Medio Ambiente del Gobierno de Aragón. Publicación digital. http://www.ipe.csic.es

Goüan, A. 1765. Flora Monspeliaca, Sistens plantas no 1850 ad sua genera relatas, et hybrida método digestas. Lugduni-Lyon.

Grytnes, J.A. \& Vetaas, O.R., 2002. Species richness and altitude: a comparison between null models and interpolated plant species richness along the Himalayan altitudinal gradient, Nepal. American Naturalist, 159: 294-304. https://doi. org/10.1086/338542

Hawkins, B.A., Felizola, J.A. \& Weis, A., 2005. The mid-domain effect and diversity gradients: is there anything to learn? American Naturalist, 166: E140-E143. https://doi.org/10.1086/491686

Humboldt, A. von, 1805. Essai sur la géographie des plantes. Chez Levrault, Schoell et Compagnie, Libraires. XIII Paris.

Izard, M., 1985. Le climat. In Végétation des Pyrénées. Carte de la végétation de la France au 200.000 (G. Dupias). Edition CNRS. Paris.

Kerguélen, M., 1993. Index synonymique de la flore de France. Collection Patrimoines Naturels, 8: 196 pp. Secrétariat de Faune et de la Flore. París.

Lapeyrouse, P. de., 1813-1818. Histoire abrégée des plantes des Pyrénées, 2 vols. + Supplément. Toulouse.
Loidi, J., 1994. Phytosociology applied to nature conservation and land management. In Song, Y., Dierschke, H. \& Wang, X. (eds.) Applied Vegetation Ecology. Proceed. 35th Symposium IAVS in Shanghai. East China Normal Univ. Press.

López-Moreno, J. I., Goyette, S. \& Beniston, M., 2005. Impact of climate change on snowpack in the Pyrenees: horizontal spatial variability and vertical gradients. Journal Hydrology, 374: 384-396, https://doi.org/10.1016/j.jhydrol.2009.06.049

Lorda López, M., 2001. Flora del Pirineo navarro. Guineana, Bilbao, 7, 557pp.

Lorda López, M., 2013. Catálogo Florístico de Navarra. Monografías de Botánica Ibérica, 11 Jolube Ed. 281 pp.

Losa, T. M. \& Montserrat, P., 1951. Aportación al conocimiento de la flora de Andorra. Actas del I Congreso del Intituto de Estudios Pirenaicos, 53: 5-184. CSIC. Zaragoza.

Montserrat Martí, J.M. \& Montserrat Martí, G., 1984. Limites chorologiques de quelques plantes pyrénéennes. Documents d'Écologie Pyrénéenne, III-IV: 323-329.

Ninot, J. M., Carrillo, A., Font, X., Carreras, J., Ferré, A., Masalles, R. M., Soriano, I. \& Vigo, J., 2007. Altitude zonation in the Pyrenees. A geobotanic interpretation. Phytocoenologia 37(3-4): 371-398 https://doi.org/10.1127/0340-269X/2007/0037-0371

Oommen, M.A. \& Shanker, K., 2005. Elevational species richness pattern emerge from multiple local mechanisms in Himalayan woody plants. Ecology, 86: 3039-3047 https:// doi.org/10.1890/04-1837

Pimm, S.L. \& Brown, J.H., 2004. Domains of diversity. Science, 304: 831-833. https://doi.org/10.1126/science.1095332

Quer, J., 1762. Flora española o historia de las plantas que se crían en España. Madrid.

Rahbek, C., 1995. The elevational gradient of species richness: a uniform pattern? Ecography, 18: 200-205. https://doi. org/10.1111/j.1600-0587.1995.tb00341.x

Ramond, L.F.E., 1801. Voyages au Mont Perdu et dans les parties adjacentes des Pyrénées. Paris.

Rübel, E., 1917. Anfänge und Ziele der Geobotanik.

Saule, M., 1991. La grande Flore ilustrée des Pyrénées. Editions Milan-Randonnées Pyrénéennes. 765pp.

Saule-Sorbé, H. \& Largier, G., 2010. Les botanistes de la flore pyrénéenne. Les feuilles du pin à crochets $9: 1-311$.

Solé i Sabarís, L. 1951. Los Pirineos. Barcelona.

Takhtajan, A., 1986. Floristic regions of the world. 522pp.

Tison, J.M. \& Foucault, B. de. (coords.) 2014. Flora Gallica. Flore de France. Biotope, Mèze, xx + 1196p.

Tutin, T. G. et al. (eds.), 1964-1980. Flora Europaea, 5 vols. Cambridge University Press. Cambridge.

Vigo, J., 1976. L'Alta muntanya catalana. La flora y vegetació. Centre Excursionista de Catalunya. Editorial MontblancMartín, $421 \mathrm{pp}$.

Villar, L., 1980. Catálogo florístico del Pirineo occidental español. Publicaciones del Centro Pirenaico de Biología Experimental, Vol. 11: 422 pp., Jaca (Huesca).

Villar, L., Sesé, J. A. \& Ferrández, J. V., 1997-2001. Atlas de la Flora del Pirineo Aragonés, 2 vols. Instituto de Estudios Altoaragoneses-Consejo de Protección de la Naturaleza. Huesca y Zaragoza.

Villar, L. y Sesé, J.A. 1991. Bibliografía botánica del pirineo aragonés. Lucas Mallada 3: 137-175. Huesca.

Walter, H. 1954. Klimax und zonale Vegetation. Festschr. Aichinger. Viena

Walter, H. \& Straka, H., 1970. Arealkunde. Floristisch-historische Geobotanik. E. Ulmer, Stuttgart, 478p.

Willkomm, M., 1893. Supplementum Prodromi Florae Hispanicae. 370 pp. E. Schweizerbart. Stuttgart.

Willkomm, M. \& Lange, J., 1861-1880. Prodromus Florae Hispanicae. 3 vols. E. Schweizerbart. Stuttgart.

Zetterstedt, J. E., 1857. Plantes vasculaires des Pyrénées principales. 330 pp. Librairie A. Frank. París. 